\title{
EVALUASI TERHADAP FASILITAS PARKIR MOBIL DI BANDARA HALIM PERDANAKUSUMA UNTUK MENINGKATKAN KEPUASAN PENGGUNA
}

\author{
Ni Luh Putu Shinta Eka Setyarini ${ }^{1}$, Dewi Linggasari ${ }^{2}$, Aniek Prihatiningsih ${ }^{3}$, dan Rakhmat \\ Thabroni $^{4}$
}

\author{
${ }^{1}$ Program Studi Teknik Sipil, Universitas Tarumanagara Jakarta \\ Email: niluhs@ft.untar.ac.id \\ ${ }^{2}$ Program Studi Teknik Sipil, Universitas Tarumanagara Jakarta \\ Email: dewil@ft.untar.ac.id \\ ${ }^{3}$ Program Studi Teknik Sipil, Universitas Tarumanagara Jakarta \\ Email: aniekp@ft.untar.ac.id \\ ${ }^{4}$ Program Studi Teknik Sipil, Universitas Tarumanagara Jakarta \\ Email: rakhmat.325170133@stu.untar.ac.id
}

\begin{abstract}
Airport parking became one of the most serious problems due to the high usage of private vehicles in airport activities. This has made a demand for parking facilities to provide a better service. There are several parameters that was the foundation of this research. For the Customer Satisfaction Index (CSI), the result shows that the user was very satisfied with the performance and facilities that was given by the airport authorities. Whereas the field observation result shows that there are several points that needed to be fixed such as pedestrian that supposed to accommodate the visually impaired persons, parking arrangements, trolley arrangements, etc. In this research, design will be made based on the recommendation that was given in research on the user feedback to the parking facilities in Halim Perdanakusuma airport
\end{abstract}

Keywords: Airport, Parking Facilities, User Satisfaction, Customer Satisfaction Index (CSI).

\section{ABSTRAK}

Permasalahan parkir di Bandara diakibatkan oleh Sebagian besar calon penumpang menuju dan Kembali dari Bandara menggunakan kendaraan pribadi, yang mewajibkan pengelola parkir untuk dapat selalu memberkan pelayanan yang baik. Pada penelitian yang menjadi dasar dilaksanakannya Pengabdian Kepada Masyarakat ini, untuk kepuasan pengguna (CSI) diperoleh hasil bahwa pengguna merasa sangat puas terhadap kinerja dan fasilitas yang diberikan oleh pihak bandara. Sedangkan pada hasil dari metode observasi lapangan terdapat beberapa hal yang perlu diperbaiki antara lain pedestrian yang mengakomodasi para penyandang disabilitas tunanetra, pengaturan parkir, penataan troli dll. Pada pengabdian masyarakat ini akan membantu pihak pengelola membuat perancangan yang sesui dengan rekomendasi penanganan yang diperoleh dari pengguna terhadap fasilitas taman parkir di Bandara Halim Perdanakusuma.

Kata kunci: Bandara, Fasilitas Parkir, Kepuasan Pengguna, Customer Satisfaction Index (CSI).

\section{PENDAHULUAN}

Penggunaan kendaraan pribadi sangat dominan saat ini, akibat dari fasilitas transportasi umum yang belum sesuai harapan bagi Sebagian besar masyarakat,sehingga menyebabkan kemacetan dan lamanya waktu perjalanan akibat dari kemacetan. Dampak lainnya adalah memperoleh tempat parkir kendaran (Mingardo, 2016). Menurut Dinas Perhubungan Provinsi DKI Jakarta, kendaraan pribadi di tahun 2019 berjumlah 2.805 .989 unit sehingga lokasi parkir mobil penumpang mengalami ketidakseimbangan antara lahan parkir yang lebih sedikit dengan kebutuhan parkir yang besar. Parkir pun menjadi berpengaruh penting terhadap transportasi karena hampir semua perjalanan dimulai dan berakhir di tempat parkir (Christiansen, et al., 2016). Menurut Ilosa, et al. (2016), usaha yang dilakukan untuk menangani masalah tersebut, adalah dengan pengadaan lahan parkir yang cukup dan membuat bentuk permodelan parkir yang tepat pada lahan parkir yang ada. 
Parkir juga mempengaruhi pergerakan kendaraan, dimana laju kendaraan melambat karena kendaraan yang berhenti di badan jalan (Chaniotakis, 2014) oleh sebab itu lahan parkir menjadi sesuatu yang sangat penting, meski parkir di lahan parkir umumnya lebih mahal, tetapi memiliki ketersediaan yang pasti dan akan mengurangi waktu tunggu untuk mencari parkir (Lee, et al., 2017). Kendaraan pribadi merupakan moda transportasi yang paling nyaman dan fleksibel dalam hal waktu tempuh dan pencapaian lokasi, sehingga kendaraan pribadi menjadi angkutan utama dari dan ke bandara di seluruh dunia (Budd, et al., 2013). Kebutuhan penggunaan parkir yang tinggi di bandara, baik untuk motor ataupun mobil pribadi mengakibatkan mengakibatkan kebutuhan meningkat dari waktu ke waktu, sedangkan lahan yang tersedia untuk areal parkir jumlahnya belum dapat menampung keseluruhan kendaraan yang akan menggunakan areal parkir (Putri, et al., 2017).

Peningkatan pergerakan penumpang dari dan ke bandara membutuhkan pelayanan fasilitas parkir yang memadai, oleh karena itu fasilitas parkir diharuskan untuk dapat memberi pelayanan yang baik untuk mendukung fungsi dari fasilitas utama (Ardi dan Dewanti, 2019). Dikatakan juga oleh Dewi dan Setyarini (2020), ketersediaan lahan parkir yang efektif sangat diperlukan untuk menghindari terjadinya penumpukan pengunjung sehingga dapat menimbulkan rasa ketidakpuasan terhadap fasilitas parkir. Dikatakan juga oleh (Ngo, 2018) bahwa kepuasan pelanggan yang lebih tinggi memberi keuntungan yang lebih tinggi terhadap fungsi dari gedung, hal tersebut dikarenakan kepuasan pelanggan menentukan keberhasilan dan kegagalan suatu manajemen gedung. Menurut Ilosa, et al. (2016), dalam usaha menangani masalah tersebut, maka diperlukan pengadaan lahan parkir yang cukup dan penentuan bentuk permodelan parkir yang tepat, dimana kebutuhan akan lahan parkir (demand) dan prasarana yang dibutuhkan (supply) haruslah seimbang dan disesuaikan dengan karakteristik perparkiran.

Dengan dilaksanakannya evaluasi kinerja fasilitas parkir mobil di Bandara Halim Perdanakusuma, akan dapat dilihat apakah sudah sesuai dengan hasil observasi, selain kinerja juga untuk mengetahui kondisi rambu dan marka serta kedisiplinan petugas / pengguna di Bandara Halim Perdanakusuma. Observasi juga dilaksanakan terhadap akses dan fasilitas pedestrian untuk difabel apakah sudah tersedia dan memberikan rekomendasi yang tepat sesuai dengan peraturan dan perundangan yang berlaku.

Pengabdian Kepada Masyarakat ini diharapkan dapat memberikan masukan kepada pihak pengelola parkir Bandara Halim Perdanakusuma tentang sektor-sektor yang perlu ditingkatkan, sesuai dengan keluhan yang disampaikan oleh pelanggan. Penanganan dan perbaikan fasilitas parkir ditinjau dari peraturan yang berlaku dan syarat minimal pelayanan (SPM) dari fasilitas parkir sesuai dengan Peraturan Pemerintah (PP) Republik Indonesia no. 2 tahun 2018.

Seperti yang dikatakan oleh Jocunda, et al. (2014), daya tarik kawasan dengan tingkat mobilitas barang dan manusia yang tinggi, menciptakan pergerakan lalu lintas yang padat. Akibatnya, terjadi peningkatan kebutuhan ruang parkir di Kawasan komersial. Kendaraan pribadi merupakan moda yang paling nyaman dan fleksibel dalam hal waktu tempuh sehingga moda ini menjadi sangat dominan di seluruh dunia (Budd, et al., 2013). Kenaikan jumlah penumpang di Gedung terminal akan membuat pelayanan bangunan penunjang juga harus ditingkatkan, salah satunya fasilitas parkir. Oleh karena itu fasilitas parkir diharuskan dapat memberi pelayanan yang baik untuk mendukung dan meningkatkan pendayagunaan gedung. (Ardi dan Dewanti, 2019). Dikatakan juga oleh Dewi dan Setyarini (2020), ketersediaan lahan parkir yang efektif sangat diperlukan untuk menghindari terjadinya penumpukan pengunjung dan tentunya dapat menimbulkan rasa ketidaknyamanan dan ketidakpuasan terhadap fasilitas parkir.

\section{Pengendalian / pengaturan parkir}


Pengendalian usaha parkir merupakan upaya untuk meningkatkan efisiensi pengusahaan parkir tanpa mempengaruhi hasil pekerjaan, yang merupakan program yang harus diselenggarakan dan dilakukan secara cermat dan secara terus-menerus. Ketika permintaan parkir telah melebihi ketersediaan lahan, maka akan terjadi peningkatan jumlah kendaraan yang parkir/berhenti di sembarang tempat. Pengendalian dengan cara menerapkan pembatasan waktu dan peningkatan biaya, sangat terkait dengan usaha untuk menyeimbangkan supply and demand dan pengembalian investasi untuk pembangunan prasarana serta biaya perawatan. Kebijaksanaan ini dinilai sangat efektif untuk meningkatkan pelayanan jaringan parkir, seperti dikutip di Pedoman Perencanaan dan Pengoperasian Fasilitas Parkir, Dir Jen. Perhubungan Darat, 1998:

a. Pembatasan lokasi parkir, dimaksudkan agar dapat mengendalikan arus lalu lintas mobil pribadi di suatu lokasi atau untuk membebaskan tempat tertentu dari kendaraan yang on street parking

b. Pembatasan waktu parkir pada lokasi tertentu, misalnya pada jam sibuk pagi harus bebas parkir karena akan digunakan untuk berlalu lintas.

c. Penetapan tarif parkir yang optimal sehingga pendapatan asli daerah dapat dioptimalkan tanpa mengganggu arus lalu lintas.

d. Pembatasan waktu parkir biasanya dengan diterapkannya tarif progresif terhadap lamanya waktu parkir.

\section{Standar penyediaan ruang parkir}

Pembangunan lahan parkir harus memenuhi SPM, yang merupakan jumlah tempat parkir yang dibutuhkan untuk menampung kendaraan berdasarkan fasilitas dan fungsi guna lahan. Kebutuhan parkir akan disesuaikan dengan jenis kegiatan, tata guna lahan dan lokasinya. Misalnya pusat pertokoan yang berada di pusat kota akan berbeda kebutuhan parkirnya dengan yang berada di pinggiran kota. Standar penyediaan ruang parkir yang dikeluarkan oleh Urban Land Institute untuk pusat perbelanjaan dalam studinya Parking Requirements for Shopping Centers pada tahun 1982 mengeluarkan rekomendasi sebagai berikut:

a. 4 slot parkir dengan luas 1,000 feet ${ }^{2}$ (304.8 meter) luas lantai kotor, 4 slot parkir untuk setiap $304 \mathrm{~m}^{2}$ pusat perbelanjaan yang memiliki luas lantai $25,000-400,000 \mathrm{feet}^{2}$

b. 4 sampai 5 slot parkir dengan 1,000 feet $^{2}$ luas (304.8 meter) luas lantai kotor, atau 4-5 slot parkir untuk setiap $304 \mathrm{~m}^{2}$ untuk pusat perbelanjaan yang memiliki luas lantai 400,000600,000 feet $^{2}$.

c. 5 slot parkir untuk 1,000 feet $^{2}$ (304.8 meter) luas lantai kotor atau 5 slot parkir untuk setiap $304 \mathrm{~m}^{2}$ pusat perbelanjaan yang memiliki luas lantai keseluruhan diatas $600,000 \mathrm{feet}^{2}$.

\section{Pemeliharaan parkir}

Menurut (Abubakar, et al., 1998) dalam (Muzakir, 2014), pemeliharaan perparkiran untuk menjamin agar pelataran parkir tetap dalam kondisi baik, pemeliharaan dengan cara: Sekurangkurangnya setiap hari dibersihkan agar bebas dari sampah dan air yang tergenang, Pelataran parkir yang sudah berlubang-lubang ditambal atau diperbaiki secara rutin pada saat tertentu.

Adapun fasilitas penunjang parkir yang memerlukan pemeliharaan adalah sebagai berikut: pos jaga, lampu penerangan, pintu masuk dan keluar, alat pencatat waktu elektronis, pintu elektronis.

\section{Perlengkapan fasilitas parkir dalam gedung}

Perlengkapan fasilitas parkir di dalam gedung meliputi (Brierley, 1972):

a. Fasilitas perlengkapan rambu dan marka, di lokasi parkir harus harus tepat penempatannya dan dapat dilihat dengan jelas, serta dipelihara kondisinya secara berkala. Sedangkan area dimana kendaraan tidak boleh lewat ditandai dengan kerb atau garis diagonal. 
b. Peralatan Pemadam Kebakaran Ringan (APAR), harus disediakan dengan jumlah yang cukup di setiap lantainya gedung parkir, dan ditempatkan pada posisi yang mudah dijangkau. Hal ini untuk mencegah meluasnyakebakaran apabila terjadi kebakaran kecil di area parkir.

\section{Standar Pelayanan Minimal (SPM)}

Peraturan Pemerintah (PP) Republik Indonesia no. 2 tahun 2018 mengenai SPM ketentuan mengenai jenis dan mutu pelayanan dasar yang merupakan urusan pemerintahan yang wajib dan berhak diperoleh setiap warga negara secara minimal.

Merupakan urusan pemerintahan yang wajib diselenggarakan Pemerintah baik Pemerintah Provinsi maupun Pemerintah Daerah. Urusan Pemerintahan wajib yang berkaitan dengan SPM terdiri atas, Pendidikan, Kesehatan, Pekerjaan Umum dan Penataan Ruang, Perumahan Rakyat dan Kawasan permukiman, Ketentraman, ketertiban umum dan perlindungan masyarakat, dan Sosial.

Kepuasan pengguna merupakan tingkat kepuasan seseorang setelah membandingkan kinerja yang dirasakan dengan harapannya. Konsumen secara umum akan mengalami 3 kondisi perasaan antara lain: kalau kinerja di bawah harapan, konsumen akan merasa kecewa, bila kinerja sesuai dengan harapan pelanggan akan merasa puas dan apabila kinerja melebihi harapan maka pelanggan sangat puas, senang dan sangat gembira. (Sunyoto, 2013)

Menurut Kotler (2008), perusahaan dapat meningkatkan kepuasan pengguna dengan memaksimalkan pengalaman yang menyenangkan melalui pelayanan yang memuaskan dan meminimalkan yang kurang menyenangkan. Pada akhirnya kepuasan pelanggan menciptakan loyalitas kepada perusahaan yang memberikan kualitas pelayanan yang memuaskan. (Kotler, 2008), Konsep pelayanan yang baik akan memberikan peluang bagi perusahaan untuk bersaing dalam merebut konsumen. Sedangkan kinerja yang berkualitas akan menimbulkan suasana kerja yang kompetitif dimana dapat diimplementasikan melalui strategi untuk meyakinkan konsumen, dan memperkuat brand.

\section{METODE PELAKSANAAN PKM}

\section{Studi pustaka}

Pada tahap ini dilakukan studi pustaka, yaitu memperdalam pengetahuan dengan mencari saran dari Pengabdian Kepada Masyarakat sebelumnya yang memiliki topik tentang parkir, seperti pada Pengabdian Kepada Masyarakat yang berjudul "Analisa Tingkat Kepuasan Pengguna Terhadap Fasilitas Parkir Mobil Puri Indah" yang mempunyai saran:

a. Sebelum melaksanakan Pengabdian Kepada Masyarakat ini sebaiknya meminta masukan/pendapat dari pengelola parkir supaya hasil dari peneitian ini benar-benar dapat dipakai untuk peningkatan kinerja dari pengelola parkir

b. Pada Pengabdian Kepada Masyarakat selanjutnya sebaiknya dilengkapi dengan foto keadaan setiap fasilitas parkir yang berhubungan langsung dengan setiap atribut yang digunakan.

c. Berdasarkan hasil analisis metode IPA, terjadi keanehan dimana beberapa atribut yang seharusnya dianggap penting, justru dianggap tidak penting oleh pengguna fasilitas parkir mobil mall puri indah. Dalam Pengabdian Kepada Masyarakat selanjutnya disarankan pertanyaan dalam kuesioner harus lebih detail dan menggunakan kalimat yang mudah dimengerti agar responden dapat memahami maksud dari pertanyaan yang dimaksud.

Selanjutnya dilakukan pengumpulan data-data mendukung seputar kondisi fasilitas yang akan ditingkatkan kualitasnya yaitu parkiran Bandara Halim Perdanakusuma. Data yang dikumpulkan harus dapat menambah kredibilitas pada hasil Pengabdian Kepada Masyarakat yang dilakukan. 


\section{Pengumpulan data}

Pengumpulan data dilakukan dengan survei observasi langsung, instrumen yang digunakan dalam melaksanakan survei adalah kamera dan beberapa orang surveyor. Urutan dari kegiatan adalah sebagai berikut:

1. Melakukan survei pendahuluan terhadap lokasi Lapangan Parkir dan semua fasilitasnya di Bandara halim Perdana Kusuma agar diperoleh gambaran yang lebih jelas kondisi objek terkini, Jakarta.

2. Mengurus surat perijinan dan Kerjasama untuk pelaksanaan Pengabdian kepada masyarakat dengan menghubungi pengelola lapangan parkir.

3. Persiapan peralatan survei utama. Peralatan perlu dipinjam atau dimiliki paling lambat sehari sebelum pelaksanaan. Alat yang dipergunakan harus telah terkalibrasi, sehingga diperoleh hasil yang akurat

4. Survei selanjutnya dilakukan dengan cara mengukur dan meggambar detail dari rambu dan marka, pedestrian dan fasilitas parkir serta membandingkannya dengan standar pelayanan minimum (SPM) yang seharusnya. SPM diatur dalam keputusan menteri perhubungan nomor: PM 13 tahun 2014 tentang rambu, PM 67 tahun 2018 tentang marka, PM 39 tahun 2018 tentang parkir dan beberapa peraturan tentang pelayanan parkir.

5. Melaksanakan survei berupa observasi langsung terhadap pedestrian dan seluruh fasilitas parkir di Bandara Halim Perdanakusuma dan membandingkan hasilnya dengan standar.

6. Memberikan rekomendasi terhadap permasalahan dan membuat gambar detail desain yang sesuai, serta membuat bagan alir untuk perbaikan sistem pelayanan yang dianggap kurang oleh pengguna.

7. Membuat kesimpulan dan saran Ruang Lingkup Kegiatan Pengabdian Kepada Masyarakat sesuai dengan subjek kegiatan ini adalah Evaluasi fasilitas parkir di Bandara Halim Perdanakusuma

\section{HASIL DAN PEMBAHASAN}

Hasil dari pengabdian masyarakat ini berupa rekomendasi dan rencana penanganan yang dituangkan dalam gambar detail disain dari fasilitas yang akan diperbaiki dan flowchart untuk perbaikan sistem, dari data hasil observasi yang diperoleh kemudian dilaksanakan penanganan terhadap defisiensi /kekurangan yang ada. Penanganannya berupa gambar detail disain dan harga satuan untuk dimensi fisik dan diagram alir pelaksanaan pada perbaikan sistem untuk dimensi lainnya. Pada beberapa gambar di bawah ini, merupakan hasil observasi lapangan terhadap faktor fisik, keandalan, daya tanggap, dan jaminan yang memerlukan penanganan karena pelayanannya dikeluhkan oleh konsumen. Penanganannya dapat berupa penanganan secara fisik/perbaikan bangunan dan juga berupa sistem pengelolaan yang harus diperbaiki. 


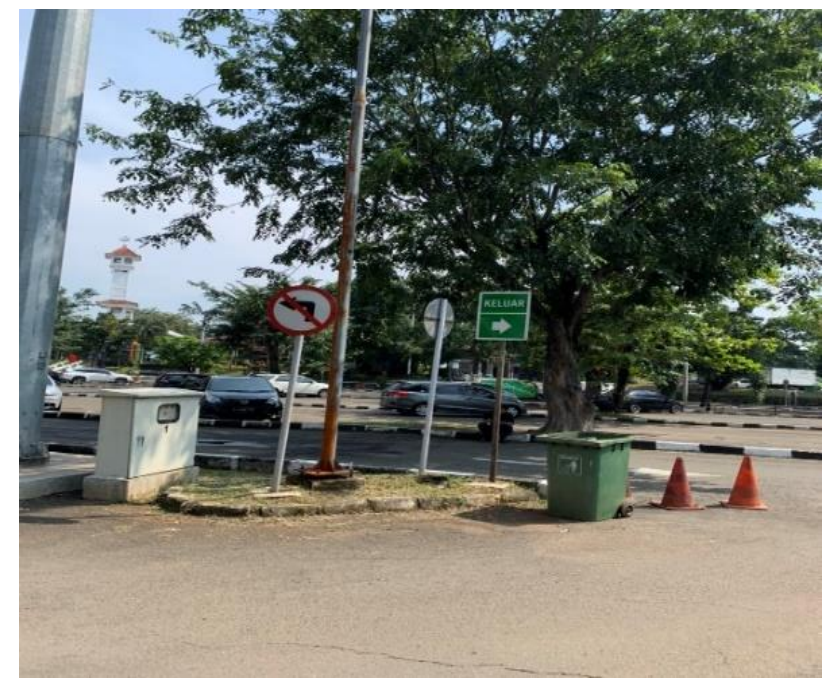

Gambar 1 Hasil observasi lapangan terhadap rambu-rambu

Pada Gambar 1 dapat diketahui bahwa:

a. Terdapat tiga rambu lalu lintas yang berdekatan di area parkir Bandara Halim Perdanakusuma.

b. Peratutan untuk acuan adalah Panduan Penempatan Fasilitas Perlengkapan Jalan Departemen Perhubungan.

c. Kondisi ini bisa membuat pengguna parkir menjadi bingung.

d. Menghilangkan salah satu rambu-rambu tersebut atau memasang rambu tidak saling berdekatan agar para pengguna parkir tidak bingung jika berada di area tersebut.

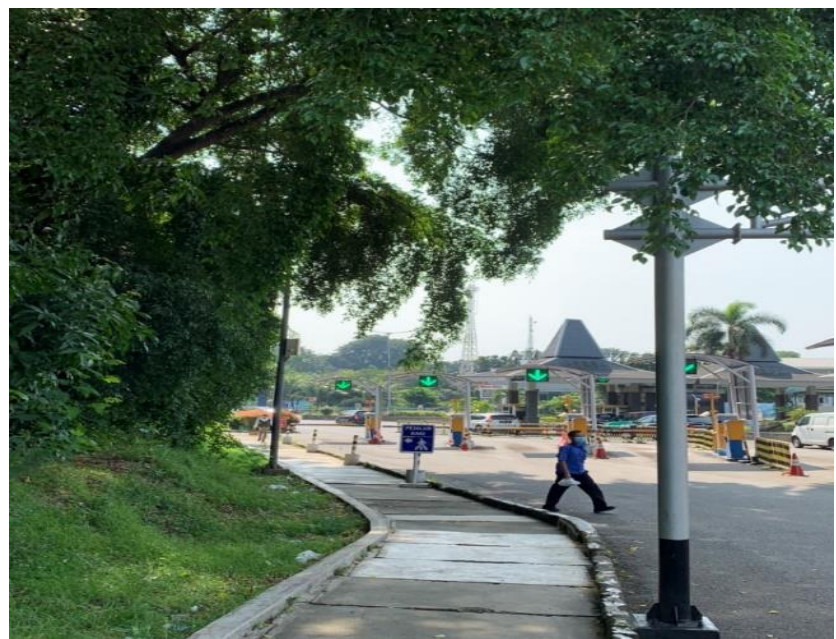

Gambar 2 Hasil observasi lapangan terhadap faktor keandalan

Gambar 2 dapat memperlihatkan bahwa:

a. Pengguna parkir sedang menggunakan trotoar untuk berjalan kaki di Bandara Halim Perdanakusuma

b. Undang-undang Nomor 22 Tahun 2009 tentang Lalu Lintas dan Angkutan Jalan

c. Kurang ramah terhadap difabel.

d. Menambahkan permukaan kasar dan keramik berulir agar memudahkan difabel dapat menggunakan trotoar. 
e. Melaksanakan pemeliharaan trotoar secara berkala agar tidak mencelakai pengguna.

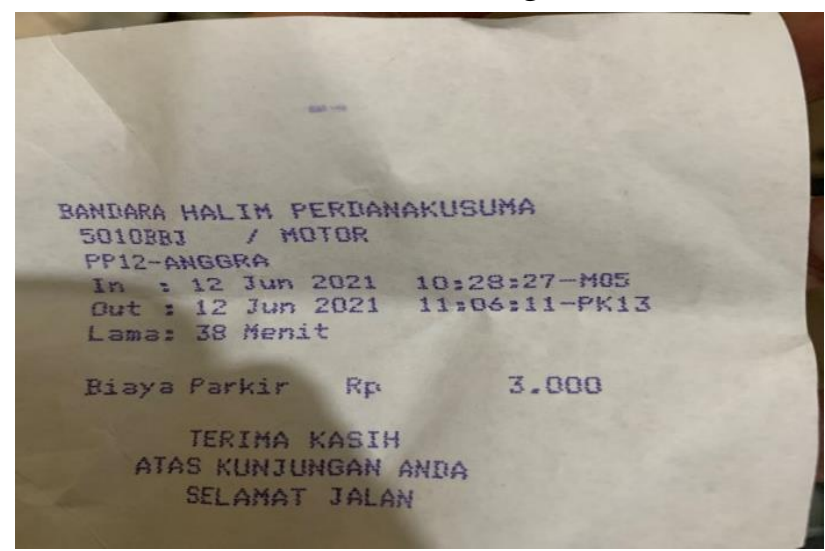

Gambar 3 Hasil observasi lapangan terhadap karcis parkir

Berdasarkan Gambar 3 dapat diketahui bahwa:

a. Karcis parkir di Bandara Halim Perdanakusuma.

b. Pergub DKI Nomor 66 tahun 2013

c. Tidak ada logo perusahaan \& nama perusahaan penyelenggara parkir.

d. Tidak ada informasi asuransi jika kehilangan barang

e. Menambahkan kelengkapan informasi pada karcis parkir.

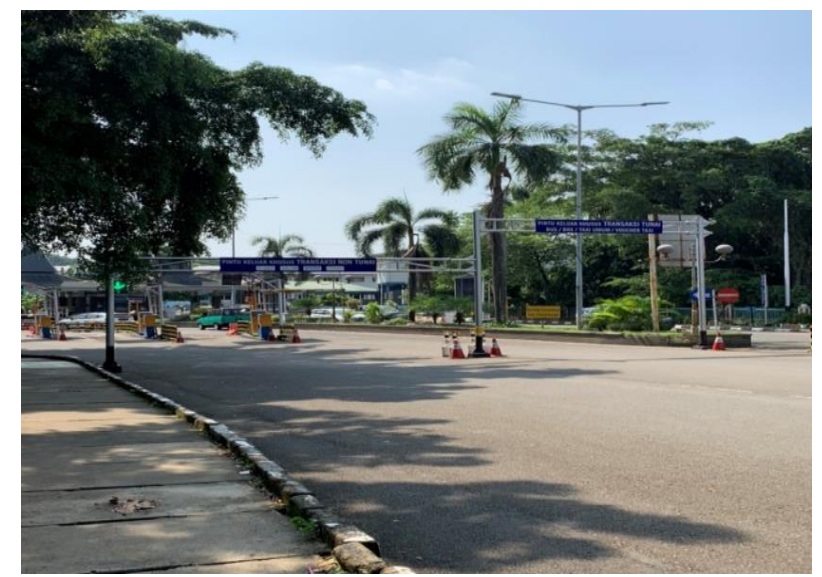

Gambar 4 Hasil observasi lapangan terhadap faktor keandalan

Berdasarkan Gambar 4 dapat diketahui bahwa:

a. Terdapat dua jenis pembayaran di loket keluar Bandara Halim Perdanakusuma, yaitu tunai dan nontunai.

b. Pergub DKI no 3 tahun 2021

c. Kurangnya opsi dalam pembayaran nontunai.

d. Menambahkan berbagai macam alternatif pada kategori nontunai agar para pengguna bisa memilih lebih banyak alternatif dalam pembayaran. 


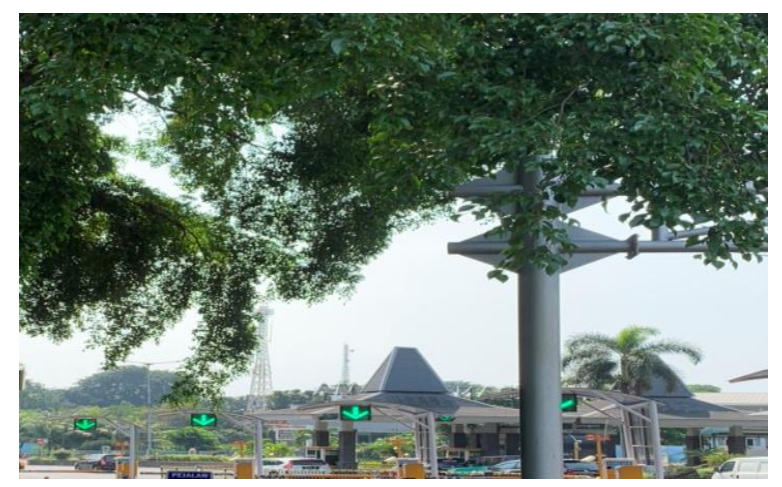

Gambar 5 Hasil observasi lapangan terhadap faktor jaminan

Berdasarkan Gambar 5 dapat diketahui bahwa:

a. Loket keluar di Bandara Halim Perdanakusuma.

b. Operator tidak sigap melayani transaksi di pintu yang menyebabkan antrian panjang.

c. Memberikan sanksi kepada petugas loket yang menghambat aktifitas pembayaran di loket pembayaran.

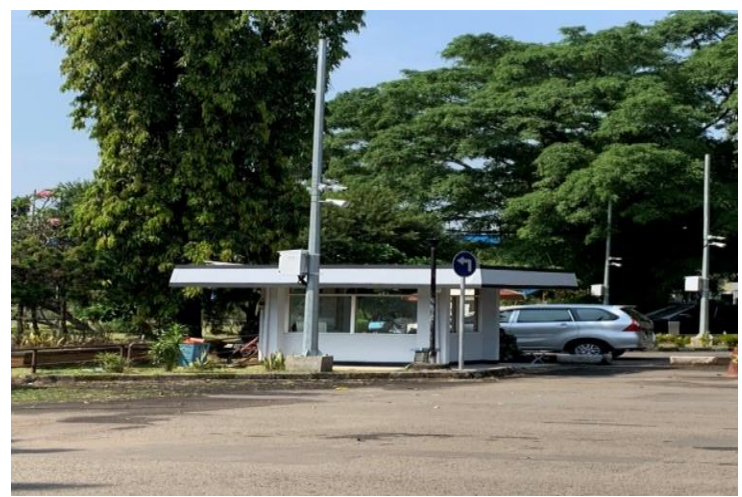

Gambar 6 Hasil observasi lapangan terhadap faktor daya tanggap

Berdasarkan Gambar 6 dapat diketahui bahwa:

a. Pos penjagaan terlihat kosong tanpa ada petugas parkir yang berjaga di area tersebut.

b. Memberi sanksi yang tegas kepada petugas parkir yang tidak berada di pos penjagaan sesuai dengan jadwal.

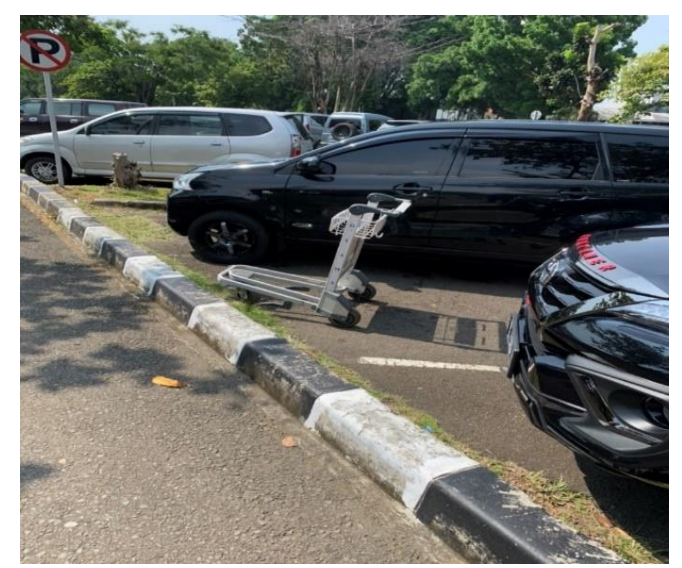

Gambar 7 Hasil observasi lapangan terhadap faktor jaminan 
Berdasarkan Gambar 7 dapat diketahui bahwa:

a. Meletakkan trolley sembarangan di lokasi parkir.

b. Peraturan yang mengakomodasi adalah Pasal 275 ayat 1 Undang-Undang Nomor 22 Tahun 2009. tentang Lalu Lintas dan Angkutan Jalan

c. Trolley mengganggu aktifitas pengguna parkir

d. Memberikan sanksi kepada para pengguna yang meletakkan Trolley dan barang sembarangan.

e. Memperbaiki sistem distribusi dan penyimpanan trolley.

f. Mengatur tugas patroli untuk petugas parkir, dan penjaga trolley di area parkir.

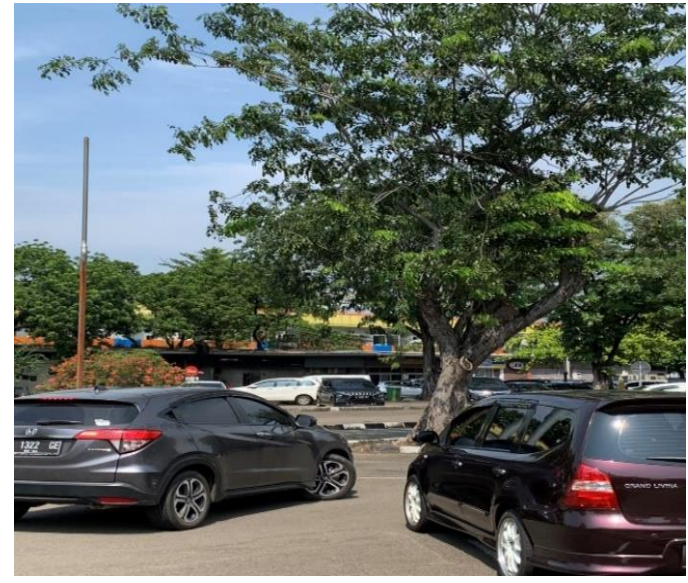

Gambar 8 Hasil observasi lapangan terhadap faktor jaminan

Berdasarkan Gambar 8 dapat diketahui bahwa:

a. Dua mobil pribadi sedang parkir di salah satu area Bandara Halim Perdanakusuma

b. Pasal 275 ayat 1 Undang-Undang Nomor 22 Tahun 2009 tentang Lalu Lintas dan Angkutan Jalan

c. Mobil parkir sembarangan yang mengganggu aktifitas pengguna parkir di area parkir bandara.

d. Petugas parkir harus menindak tegas para pelanggar agar aktifitas parkir mobil di bandara tidak terganggu.

\section{KESIMPULAN DAN SARAN}

Berdasarkan analisis metode observasi lapangan pada dimensi fisik (tangible) terdapat permasalahan, yaitu:

a. Dimensi fisik, Perlu penataan ulang terhadap rambu di area parkir bandara Halim Perdana Kusuma, dengan merancang penempetan dan ukuran rambu secara tepat sesuai dengan peraturan dan fungsinya. Untuk pedestrian harus dirancang detail desain dan dipelihara agar aman bagi pengguna dan ramah terhadap difabel

b. Dimensi keandalan (reliability) terdapat 2 permasalahan, yaitu perlu informasi yang jelas dan lengkap tercantum pada karcis parkir seperti asuransi bila terjadi kehilangan atau kerusakan. Opsi pembayaran harus tunai, sehingga perlu tambahan opsi pembayaran non tunai agar tidak menghambat akses keluar. Perlu dibuat diagram alir tahapan pelaksanaan dan dirancang 
sistem untuk dapat menghemat waktu, agar tidak terjadi antrian Panjang kendaraan di pintu masuk dan keluar parkir.

c. Dimensi daya tanggap (responsiveness) terdapat 2 permasalahan, petugas operator kurang sigap melayani transaksi dan pos penjagaan di lokasi 168 Parkir kosong tanpa petugas parkir yang berjaga.Perlu adanya sistem penjadwalan yang tepat dan ketat dengan membuat rencana jadwal dan rotasi serta sangsi bagi pelanggaran.

d. Dimensi jaminan (assurance) terdapat 2 permasalahan, yaitu trolley yang terletak sembarangan di lokasi parkir sehingga bisa mengganggu aktifitas pengguna parkir dan mobil yang parkir sembarangan di area parkir Bandara Halim Perdanakusuma. Perlu pengaturan sangsi yang tegas terhadap pengguna dan petugas trolley yang lalai

\section{Ucapan Terima Kasih (Acknowledgement)}

Pada PKM ini kami sangat berterimakasih kepada pihak pengelola parkir bandara Halim perdana Kusuma yang telah mengijinkan kami untuk dapat bekerjasama untuk dapat meningkatkan fasilitas lapangan parkir dihalim Perdana Kusuma. Kepada Lembaga Penelitian dan Pengabdian kepada Masyarakat (LPPM) UNTAR yang telah mendukung, memfasilitasi dan mendanai kegiatan PKM ini.

\section{REFERENSI}

Abubakar, I., Sinaga, E. A., Budiarso, Sinulingga, T., Agung, T. G., Sembiring, N., . . Sutiono, E. (1998). Pedoman Perencanaan dan Pengoperasian Fasilitas Parkir. Jakarta: Direktorat Bina Sistem Lalu Lintas Angkutan Kota dan Direktorat Jenderal Perhubungan Darat. http://hubdat.dephub.go.id/spesial-konten/pustaka/literatur/transport-umum/514-pedomanperencanaan-dan-pengoperasian-fasilitas-parkir/download.

Ardi, S. \& Dewanti (2019). Penataan Fasilitas Parkir Terimnal Penumpang Bandara Internasional Ahmad Yani Semarang. Yogyakarta: Universitas Gadjah Mada. http://etd.repository.ugm.ac.id/penelitian/detail/168669

Brierley, J. (1972). Parking of Motor Vehicles. London: Applied Science Publishers Limited.

Budd, L., Ison, S., \& Budd, T. (2013) An Empirical Examination of the Growing Phenomenon of Off-site Residential Car Parking Provilion: The Situation at UK Airports. Transportation Research Part A: Policy and Practice, 54, 26-34. http://dx.doi.org/10.1016/j.tra.2013.07.006

Chaniotakis, E. (2014). Parking Behavioural and Assignment Modelling: Methodology and application for the evaluation of Smart Parking applications: Delft University of Techonology.https://www.semanticscholar.org/paper/Parking-Behavioural-and-

Assignment-Modelling\%3A-and Chaniotakis/7b9da17371830c9e731402529855f9ae929979b1

Christiansen, P., Engebretsen, Ø., Fearnley, N., \& Hanssen, J. U. (2016). Parking facilities and the built environment: Impacts on travel behaviour. Transportation Research Part A: $\begin{array}{llll}\text { Policy and } \quad \text { Practice, } & \text { 95, }\end{array}$ https://www.sciencedirect.com/science/article/pii/S0965856416301525

Dewi, C.K. \& Setyarini, NLPSE. (2020). Analisis Tingkat Kepuasan Pengguna Terhadap Fasilitas Parkir Mobil Mall Puri Indah. Jurnal Mitra Teknik Sipil, 3 (3), 659-670. http://dx.doi.org/10.24912/jmts.v3i3.8386

Dinas Perhubungan DKI Jakarta. (2019, Maret 21). Jumlah Kendaraan Bermotor Menurut Jenis Kendaraan (unit) di Provinsi DKI Jakarta 2018-2020. Diakses dari 
https://jakarta.bps.go.id/indicator/17/786/1/jumlah-kendaraan-bermotor-menurut-jenis kendaraan-unit-di-provinsi-dki-jakarta.html 13 Februari 2021.

Ilosa, A. (2016). Kualitas Pelayanan Parkir di Tepi Jalan Umum Kota Yogyakarta. Jurnal Natapradja, 4 (2), 107-126. https://doi.org/10.21831/jnp.v4i2.12619

Jocunda, S. (2014). Karakteristik Ruang Parkir di Pusat Perbelanjaan Jalan Tanjungpura Kota $\begin{array}{llllr}\text { Pontianak. Jurnal } & \text { Arsitektur, } & 1 & \text { (1), } & \text { 155-162. }\end{array}$ http://dx.doi.org/10.26418/lantang.v1i1.18806

Kotler, P. (2008). Manajemen Pemasaran. Jakarta: Indeks.

Lee, J., Agdas, D., \& Baker, D. (2017). Cruising for parking: New empirical evidence and influential factors on cruising time. Journal of Transport and Land Use, 10 (1), 931-943. https://doi.org/10.5198/jtlu.2017.1142

Mingardo, G. (2016). Articles on Parking Policy: Delft University of Techonology. https://www.verkeerskunde.nl/Uploads/2016/11/ProefschriftGiulianoMingardo.pdf

Muzakir, A. (2014) Evaluasi Kapasitas dan Penataan Ruang Parkir Rumah. Skripsi Jurusan Teknik Sipil, Fakultas Teknik Universitas Atma Jaya Yogyakarta, 54, 26-34. http://dx.doi.org/10.1016/j.tra.2013.07.006

Muzakir, A. (2014). Evaluasi Kapasitas dan Penataan Ruang Parkir Rumah. Yogyakarta: Universitas Atma Jaya. http://e-journal.uajy.ac.id/id/eprint/5128.

Ngo, V. M. (2018). Measuring Customer Satisfaction: A Literature Review. Proceedings of the 7th International Scientific Conference Finance and Performance of Firms in Science, Education and

Practice,

1637-1654. https://www.researchgate.net/publication/318827962_MEASURING_CUSTOMER_SATI SFACTION_A_LITERATURE_REVIEW

Putri, G. A., Suthanaya, A. P. , Ariawan, A. M. (2017). Analisis Karakteristik dan Kebutuhan Parkir di Bandara Internasional I Gusti Ngurah Rai Bali. Jurnal Spektran, 5 (2), 155-162. https://ojs.unud.ac.id/index.php/jsn/article/view/32938

Republik Indonesia (2018) Peraturan Pemerintah No. 2 Tentang Standar Pelayanan Minimal

Sunyoto, D. (2013). Teori, kuesioner \& analisis data untuk pemasaran dan perilaku konsumen. Yogyakarta: Graha Ilmu. 
Seminar Nasional Hasil Penelitian dan Pengabdian Kepada Masyarakat 2021

Pengembangan Ekonomi Bangsa Melalui Inovasi Digital Hasil Penelitian dan

Pengabdian Kepada Masyarakat

Jakarta, 21 Oktober 2021

(halaman kosong) 